\title{
A Practical Approach to Strategy Development
}

\author{
Markus Schwaninger
}

This article dea/s with methodology, i.e. the principles of laying out effective methods for strategy development. It does not describe the multitude of relevant methods in detail but presents them in context, i.e. inasmuch as they are interconnected.

Several authors ${ }^{2}$ state that theories in the area of business policy and strategy have mostly been built in a non-cumulative way, i.e. that many new theories have been developed without sufficient consideration of previous research done or without adequate integration of knowledge coming from different disciplines.

This article reflects a personal attempt to overcome this limitation. Therefore, the ground covered herein is extensive. My propositions draw on extensive consulting experience, based on the systems approach. I am referring to process-oriented consulting in strategic management, known as 'Integral Corporate Development' ${ }^{\prime 3}$ in which practical action is considered in the light of relevant theories.

Here is a list of some of the theoretical concepts on which this work in strategy is based ${ }^{*}$
is General management theories (e.g. Drucker, Ulrich)

Synoptic approaches to planning (e.g. Ansoff, Gaelweiler, Steiner)

Incrementalist approaches to planning (e.g. Baybrooke/Lindblom, Quinn)

Dr Markus Schwaninger is Senior Lecturer in Management at the St Gall Graduate School of Economics, Law. Business and Public Administration.

-This article does not allow me to quote and draw on all of this background material explicitly and extensively. More solid theoretical underpinnings of the arguments and recommendations presented here are compiled in my forthcoming books Strategiefindung and Integrale Unternehmungsplanung.

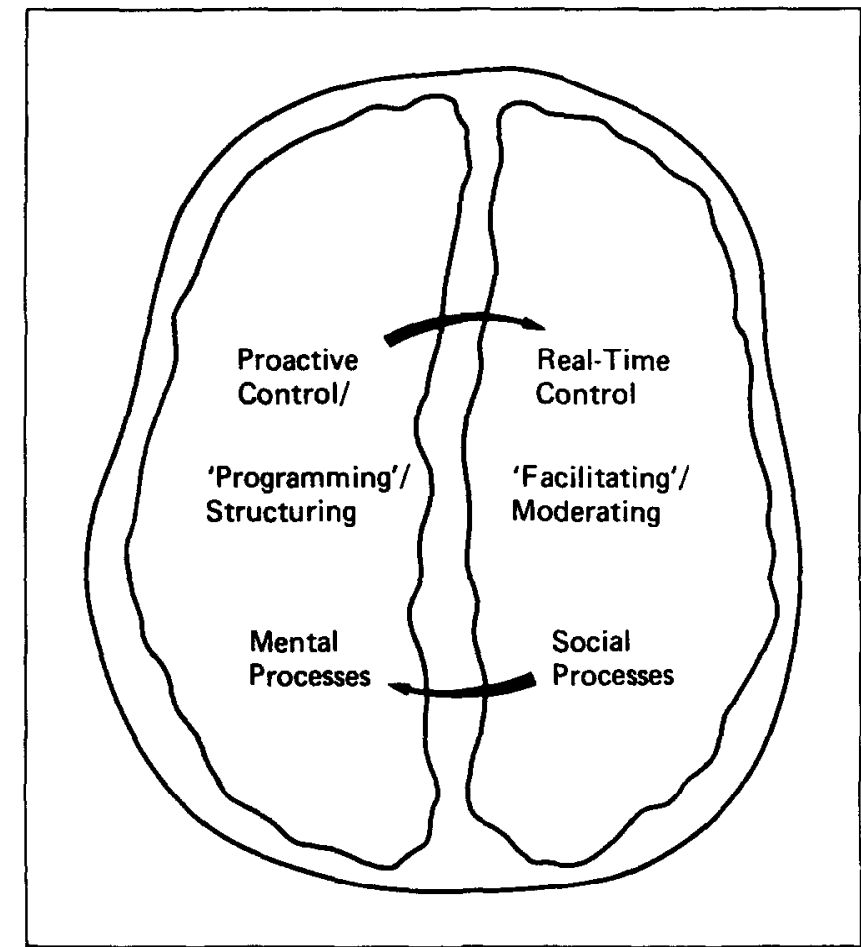

Figure 1. Functions of a methodology of strategy development $t^{1}$

is Competitive strategy research (e.g. Members of the Strategy Research Center, PIMS-Associates/SPI, Porter)

if Systems theories (e.g. Bertalanffy, Boulding, Jantsch)

is Systems methodologies (e.g. Checkland, Forrester, Vester)

is Cybernetics and systems sciences applied to management (e.g. Ackoff, Beer, Churchman, Malik)

Brain research (e.g. Eccles, Sperry, von Foerster)

it Information theory (e.g. Ashby, Shannon, Weaver) 
is Communication theories (e.g. Bateson, Watzlawick)

is Learning theories (e.g. Argyris/Schon, Pask, Piaget)

is Social psychology of organizations (e.g. Bennis, Schein, Weick).

\section{The Need for a Methodology of Strategy Development}

The term 'method' derives from the Greek words 'meta' (towards) and 'hodos' (way). It denotes, therefore, a way towards something, a tested and proven procedure, a technique or a plan of action to reach a goal.

This often involves activities which originate from a definite sequence of precisely described steps (algorithm). Such algorithms can be very useful for achieving well-known and definite goals. Numerically definable problems, or problem components (such as sorting problems, statistical calculations, inventory management, etc.; in other words, all problems that can be worked out by using rather simple computer routines) can be solved by these methods. Most applications of operations research (optimizations, forecasting models, data retrievals etc.) are, at the present time, still solved algorithmically.

In the fields of company policy and strategy, contrary to widespread belief, many problems are either indefinable, or definable only in part; often basic goals can only be vaguely recognized and formulated. Usually the corporate planner has relatively little 'hard' data to go on but all the more 'soft' data concerning values, principles, identity of the firm, challenges to meet etc., which are, to varying degrees, vague.

The planner needs methods of another natureheuristics-to master such problems. The word 'heuristic' can best be translated as 'the art of finding'. Stafford Beer defines 'heuristic' as 'a set of instructions for searching out an unknown goal by exploration, which continuously or repeatedly evaluates progress according to some known criterion'.${ }^{4}$ Heuristic methods, then, are processes which are used to search for subjects, whose contents are unknown or only partially known. This is the type of uncertainty inherent in strategic problems. The structure of the business system, the competitive situation, market positions to be aimed for, optimal thrusts and the rules of the competitive game are all subjects about which tangible information is scarce at the beginning of the search process.

The crucial problem of methodology in strategy development is to provide a set of heuristic devices-instruments and procedurcs-which fos- ter the formation of effective strategies, to ensure that the company maintains a balance with its changing environment, i.e. that it sustains its viability and identity.

Planning is the systematic anticipation of actions and their future consequences. Planning methodology is, therefore, concerned with managing the thinking processes of individuals and groups who are participating in planning as well as of the organization as a whole. It has to guarantee first, that the correct questions are asked during the planning process, and that evaluation criteria are used which build up and sustain earnings potential. ${ }^{5}$ Secondly, it should help to produce effective strategies by making use of the know-how available within the organization and by developing new insights.

This implies that the two principal streams of thought in the field of planning theory-the 'synoptic' and the 'incremental' approaches - -have to be conceived, not as antagonistic, but as complementary efforts.

A comprehensive planning methodology must embrace two types of functions (see Figure 1).

\section{(1) The Proactive Control Function}

This function is concerned with modelling and understanding the key variables that define a specific business system. The better such a model reflects reality, in patterns of behaviour and in underlying structures, the better one is able to make accurate strategic decisions.

\section{(2) The Real Time Control Function}

This function is concerned with 'coaching' the social process of strategy-making. It has to ensure that all the owners of strategy-relevant know-how participate in the process. Through the interchange of ideas, through feedback and self-correction, a learning process should take place, which leads to growth of the institutional knowledge of the organization as a whole.

The next section, which concerns the principles of process design, will include aspects of both functions. The section on planning instruments, refers to the proactive control function. In the final section, the perspective of the real time-control function will be resumed and, finally, both functions will be reintegrated under the theme of this article, which is: strategy development is the management of knowledgegaining processes.

\section{The Process Design}

During the seventies, planning endeavours were still almost exclusively aimed at constructing a system which would lead to an optimal strategy. Complex flow-charts and descriptions resulted, often containing dozens of standardized and rigidly connected 
steps. Many companies tried to implement these proccdures, often at great expense, in order to master the task of planning. Due to the poor results from many of these efforts, there has remained widespread scepticism concerning strategic planning methodology.?

An assumption frequently held is that the processes of strategy development are simply too complex for structuring but complex processes should not be highly standardized. In order to evolve there must be substantial flexibility in the interplay between the planning of separate business units and that of the overall company strategy (see Figure 2). A lack of structure, on the other hand, could result in management forgetting important steps or taking them at the wrong time.

For individual business units, the sequence of planning must be consistent with the make-up of the essential problem areas and their interrelationships. In the light of available literature on corporate planning, it seems difficult to determine which variables are 'essential' from a strategic point of view. The term 'strategic' is used frequently, because it seems to be fashionable. Most authors apparently do not worry about furnishing reliable criteria to distinguish strategic from non-strategic issues. Yet, such a distinction is not a play on words, but is of real significance. Earnings potentials are objective indicators at the strategic level, just as profit is an indicator of operational performance. A business unit or a company has an earnings potential, irrespective of whether its managers know about it or not.

Fortunately, our understanding of strategic issues has been greatly extended. Only 8 years ago, Gaelweiler ${ }^{5}$ published his theory which provides a model of the control parameters and criteria relevant on the strategic level. Until then, theory in this area had been rather fuzzy and fragmentary. Gaelweiler's model is on a par with the models of the operational level, which double-entry bookkeeping has offered us for a long time.

Gaelweiler has provided us with a comprehensive and general conceptual model to direct the mental process of planning. This model builds on the works of important authors like Ackoff, Ansoff, Henderson, Steiner and many others. It clearly identifies which groups of strategic variables are essential, how they are connected and the order in which they need to be analysed. Gaelweiler's model is the basis for the following section of this paper.

The variety which is needed to master the complexity of strategic problems can be achieved by meeting the following requirements:

(1) A number of basic planning steps is obligatory. These are determined on the basis of the model of all the factors and data relevant for strategic plans. In a separate section on work and documentation procedures, I shall come back to the question of what these basic steps are.

(2) The fundamental steps can be complemented by others, depending on the specific industrial, business or company characteristics of the case in question.

(3) The process is iterative so that considerations of previous steps can be re-assessed and the relevant conclusions modified on the basis of new information.

(4) Adequate tools are provided for the fundamental and supplementary steps to ensure that the thought processes evolve effectively, and that they can be reconstructed so as to promote institutional learning.

(5) The time available is scheduled approximately and a deadline is set.

Figure 2 is a diagram describing the introduction of a strategic planning system in medium-sized companies. Members of the consulting group of the St. Gall Management Centre have used this process model for the implementation of strategic management in many firms, several of them in the service sector, during the past 5 years. It consists of a set of modules of analysis and diagnosis, design and implementation, all of which are necessary in a company comprising several businesses. Planning considerations at corporate level are represented in the upper half of the figure; those at SBU-level in the lower half. Figure 2 contains references to the use of quantitative instruments related to the PIMS data base, to which I shall refer in the section on the design of planning techniques.

The model contains iterations, and is circular. The sequence shown in Figure 2 differs from some traditional views of planning which arc lincar, with a beginning and an end. It is based on the axiom that perception and learning are accomplished in the form of continuous, circular processes of inquiry and information processing. ${ }^{8}$ This is true of the perceptions of individuals, and also for groups and whole organizations.

The strategic planning process should be designed in a different way from the operational planning process. Experience suggests a proceeding which seems to gain increased acceptance in companies with several business units: instead of planning for all SBUs (Strategic Business Units) in one annual planning cycle, periodic strategy meetings are held several times a year, for example at monthly or bimonthly intervals. During each meeting, previous strategies of one or two business units are reviewed, revised and formulated anew. The frequency with which business units are planned is handled flexibly. It varies from unit to unit depending on their specific dynamics. Business areas with intensive competition or high rates of innovation need to be 


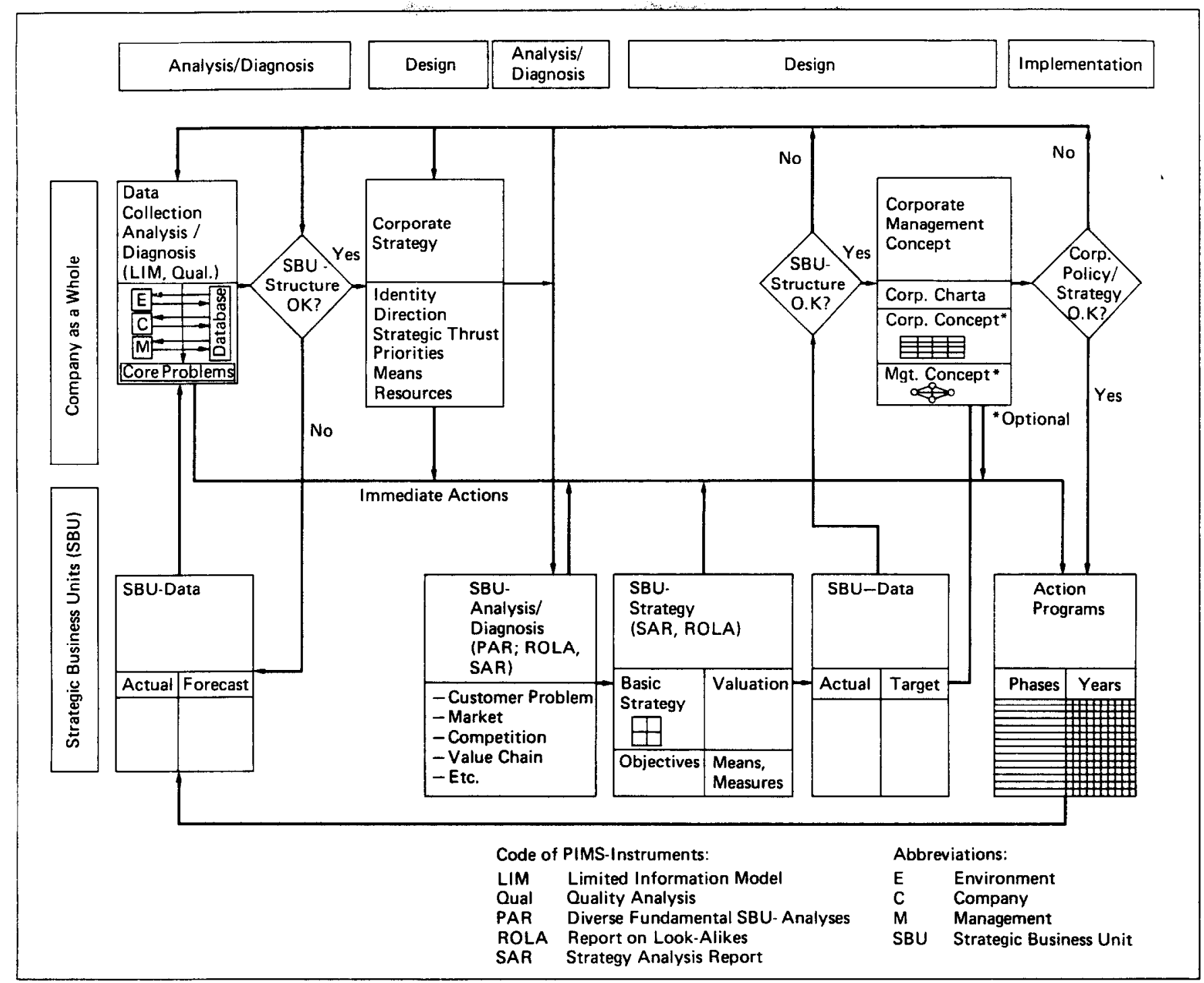

Figure 2. Process showing the interplay of corporate and SBU-levels in strategy development

dealt with more often than the ones in which less change takes place. In addition to these planning meetings within the business units, conferences to develop overall corporate strategy are necessary, although less frequently. These conferences deal with questions which cannot be answered by simply adding together the strategies of the various business units.

\section{Design of Planning Instruments}

This section describes the functions of various planning techniques. The first part deals with techniques for analysis and diagnosis, the second part with design techniques and the third part gives a synopsis of work and documentation steps in which these tools are used.

Companies are not only as different as people, but there are at least as many variations in the world of business as in the animal world. Just as veterinary surgeons have to use varying surgical instruments depending on the species of animal on which they are operating, so planners must apply specifically designed planning instruments for different divi- sions and business areas in accordance with their specific requirements. Therefore, a system of planning tools must be modular, but it has to be interconnectable as well, so that planning problems of individual units can be solved with a set of instruments tailored to their specific needs. The selection of tools should be determined primarily by the degree of detail and the coherence or segmentation of the business system in question. The instruments themselves have to be sufficiently flexible to allow for adaptation to the material, structural and terminological peculiarities of the company or part of the same. Independently, at corporate level, minimum standards of uniformity are necessary to ensure comparability and compatibility of data.

\section{Instruments for Analysis and Diagnosis}

A strategy can only be as good as the diagnosis on which it was based. The analytical phases are, therefore, of decisive importance. Figure 3 shows a set of analytical instruments designed by the author, which have been used and proven in many companies. Conceived in a modular way, these instruments are compatible and hence interconnec- 


\begin{tabular}{|c|c|c|c|c|c|}
\hline $\begin{array}{l}\text { Typical Steps of the Analysis Per } \\
\text { Business Unit }\end{array}$ & Code & 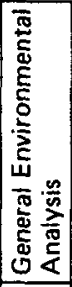 & 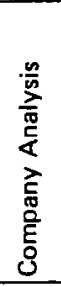 & 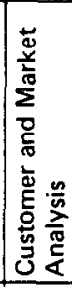 & 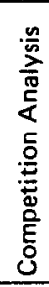 \\
\hline Customer Problem/Customer Need & $\mathrm{CP}$ & & & $x$ & \\
\hline $\begin{array}{l}\text { Problem Solutions (Including Quality/ } \\
\text { Value/Price-Performance Ratios) }\end{array}$ & PS & & & $x$ & $x$ \\
\hline Distribution Channels & DC & & $x$ & $x$ & $\mathbf{x}$ \\
\hline Value Chains & VC & & $x$ & $x$ & $x$ \\
\hline Functions in the Market & FM & & $x$ & & \\
\hline Environmental Scenario & E & $x$ & & & \\
\hline Qualititative Market Scenario & $\begin{array}{c}M \\
\text { Qual }\end{array}$ & & & $\mathbf{x}$ & \\
\hline $\begin{array}{l}\text { Quantitative Market Scenario } \\
\text { (Including Substitution Analysis) }\end{array}$ & $\begin{array}{c}M \\
\text { Quant } \\
\end{array}$ & & & $x$ & \\
\hline Product - Market - Matrix & PMM & & $x$ & $x$ & $x$ \\
\hline Portfolios & PF & & $x$ & $x$ & $(x)$ \\
\hline Key Factors & KF & & & & $x$ \\
\hline Comparison of Competitors & $\mathrm{cc}$ & & $x$ & & $x$ \\
\hline Dynamic Industry Profile & DIP & & & & $x$ \\
\hline Configuration Analysis & $\mathrm{CA}$ & & & & $x$ \\
\hline Strategic Data Pages & SD & & $\mathbf{x}$ & $x$ & $x$ \\
\hline Restrictions & R & & $x$ & $\mathbf{x}$ & $x$ \\
\hline Critical Assumptions (Premisses) & $\mathrm{CP}$ & $x$ & $x$ & $x$ & $x$ \\
\hline
\end{tabular}

Figure 3. Fields and steps of analysis

table with each other as well as with other related management systems. They are supported by computer models for data processing and simulation, which are a valuable support to the intuition and experience of those involved in the process of planning.

Most of the instruments mentioned in Figure 3 are tools for strategic analysis. An instrument which has to be explained is what I call Configuration Analysis. This method uses a morphological technique to describe a business system. ${ }^{9}$ The analysis is carried out in a qualitative way. It follows the chain of relationships between the elements of a business system, shown in Figurc 4. An cnd-uscr, or customer problem can be solved by different technologies, which produce products or services. They are delivered via distribution channels to users or customer groups which have specific problems, etc.

The sequence described is fixed and common to all kinds of business systems, while the contents (for example: the technology used) of each component and the interplay of components (for example: the link between the technology and the distribution channel) are matters for managers to decidc.

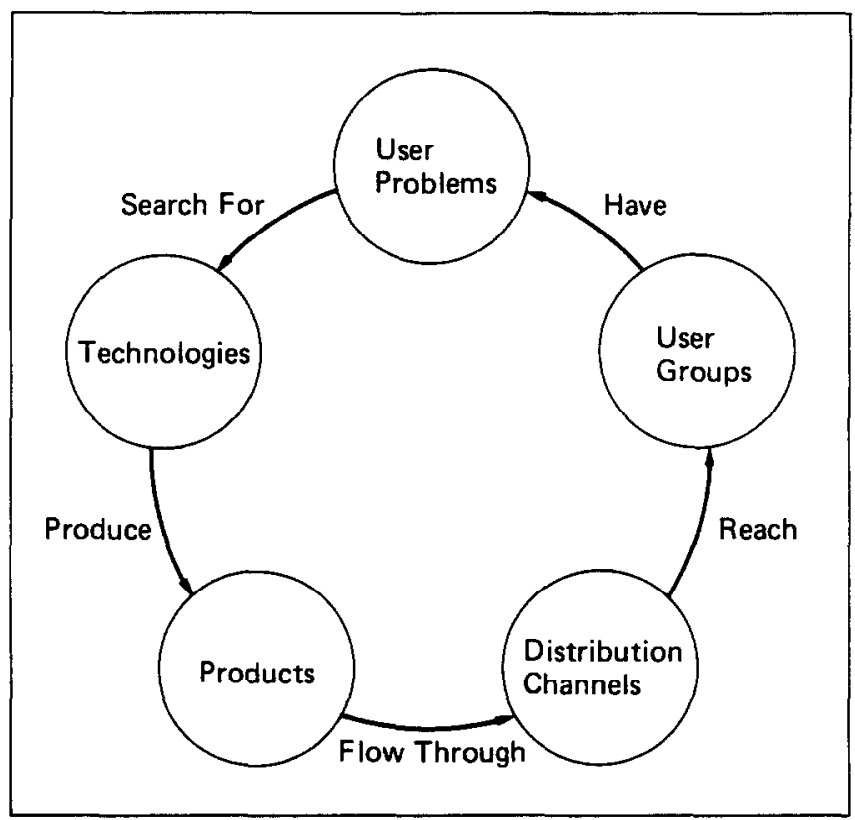

Figure 4 . The chain of relationships in a business system

Configuration Analysis is concerned with comparing the way in which competitors conceive their respective business systems (see Figure 5).

The dimensions shown in Figure 5 need further explanation. First, the analysis also includes competition, an essential variable of the business system, but which is not part of the sequence cited above. Secondly, if the context is multi-regional, the geographical aspect has to be considered as well. Thirdly, depending on the case, certain components analysed (in our example: product and technology) have to be broken down into subcomponents.

Quality is not the object of Configuration Analysis, but of the Comparison of Competitors (instrument 'CC' in Figure 3). The Configuration Analysis deals with the structural features of business systems, whilst the Comparison of Competitors compares the relative strengths of different competitors within a business system.

\section{Design Instruments}

The set of design instruments (see also Figure 6) must also ensure that no relevant questions be left unconsidered. Since wrong strategic decisions are usually irreversible, such a mistake can endanger the company in the long run. For this reason, the planning instruments must provide checks with regard to completeness and consistency of reasoning, right from the beginning of the planning process.

Also important is the documentation of the data and considerations on which the strategy is based-context, assumptions, constraints and evaluation-in a way that subsequent retracing and discussion are possible. Critical assumptions (premisses) must be 


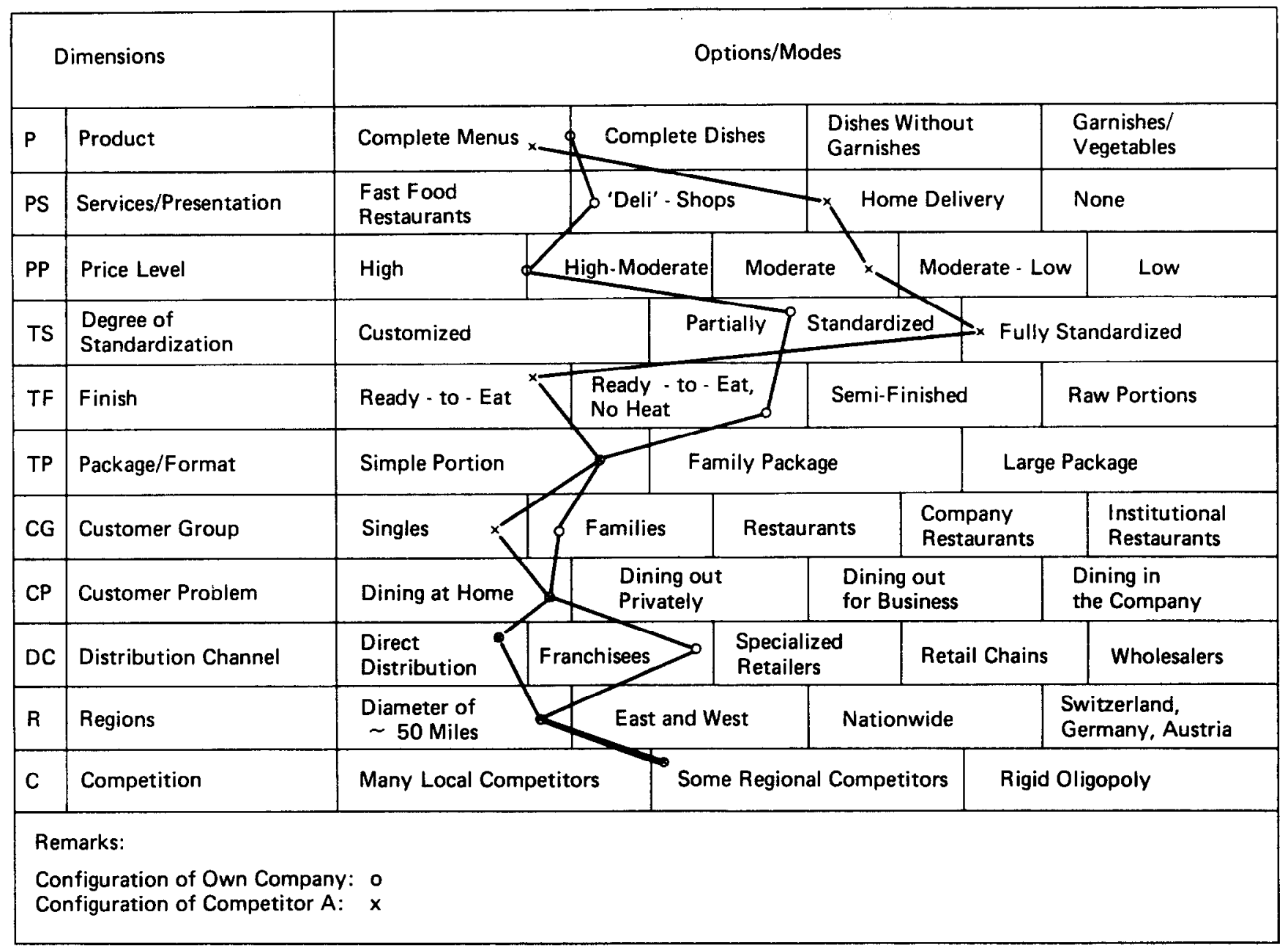

Figure 5. Configuration analysis. An example from a catering business

brought into an explicit and controllable form and continuous monitoring has to be provided.

Strategic goals are only as good as the actions taken to achieve them. Planning instruments must, therefore, not only assist the definition of prudent goals but also the creation of effective action programmes by taking advantage of the integrative capability of the human brain. The human brain is particularly suited to thinking about interconnections, to recognizing patterns, to analysing and processing problems from various levels of reflection simultaneously. Human beings are superior to computers above all due to their consciousness, which allows reflection on their own thoughts as well as distinguishing between their own thinking and the real world.

The productivity of the planning process can be substantially increased if the planning system is designed to take advantage of this human ability. It should enable objectives to be continually checked against resources and action programmes and, it should allow potential objectives to be considered in the light of the actual resources and approaches at the company's disposal. Often, planning systems lack this ability, because goals, resources and action programmes were defined separately from each other, at different times and by different people. This can lead to unrealistic objectives and an imbalance between goals and resources, e.g. where the resources and programmes related to a specific objective are quantitatively or qualitatively inadequate.

\section{The Strategy Page}

In Table 1 a proven and tested planning tool ${ }^{10}$ is shown which illustrates the interactive development of goals, resources and action programmes. Despite the use of sophisticated analytical instruments, heuristics, quantitative methods, computer-aided evaluation techniques and simulation models to find strategies, this simple Strategy Page is still an important element of the planning methodology presented herein. It was created to elaborate and summarily document business strategies or strategy options. This tool is constructed in such a way as to unite the crucial strategy data-business idea and strategic direction ('basic strategy'), context, evaluation, goals, means and action programmes-on one $\mathrm{A} 3$ form. The text can and should refer to more detailed documents. Empirical evidence after using this tool with over 1000 planning specialists and managers $^{11}$ supports the hypothesis that its layout enhances integral thinking, communication and effective strategy realization. 
Table 1. Strategy Page

\begin{tabular}{|c|c|c|}
\hline \multirow{3}{*}{ Example: } & Strategy & Code: $\mathbf{S 1 . 1}$ \\
\hline & \multirow{2}{*}{ SBU: (A) Inventory and Transport Systems for Restaurant Chains } & Page: 1 \\
\hline & & Treatm.: $10 / 85$ \\
\hline
\end{tabular}

Basic strategy

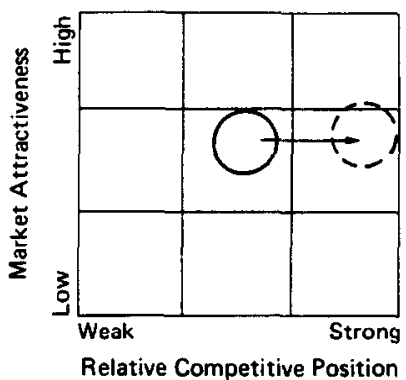

Basic strategy

To establish ourselves as the leading all-round problem-solver for storage and transport systems to a defined number of restaurant chains. To develop the innovation potential together with the restaurant chains as a basis for our other business units. Market leadership in West Germany, France and the Benelux countries. Use of the experience curve

\section{Context}

-restaurant chains in progress (compare DC 1.1)

-shorter investment cycles

-more funds for investments in productivity

-intensified competition

-on the level of the general 'outfitters'

-general outfitters vs specialists

$\begin{array}{lccc}- \text { Market volume: } & 1985 & \text { growth p.a. } & 1991 \\ -\mathrm{D} & \ldots \ldots \ldots & \ldots \ldots \ldots & \ldots \ldots \ldots \\ \text {-F } & \ldots \ldots \ldots & \ldots \ldots \ldots & \ldots \ldots \ldots \\ \text {-Benelux } & \ldots \ldots \ldots & \ldots \ldots \ldots & \ldots \ldots \ldots\end{array}$

Evaluation

\section{Strengths/Advantages/Opportunities}

-most comprehensive supply of all competitors

- product quality/customer benefit (incl. system analysis and design)

-highest innovation rate

-mediation of international engineering know-how

- performance image (compare MS 3/85)

-leadership in the fast food sector

-production (all under one roof)

\section{Weaknesses/Disadvantages/Threats}

- complexity of the production and logistics systems

-trend towards general outfitter (compare MS 7/85)

-dispersed marketing

-product opportunities missed

-price-cost structure (compare DC 5.1)

-effectiveness of delivery

-personalization in upper management, weaknesses in middle management

- location

-management and training of the sales workforce

Objectives, means, measures

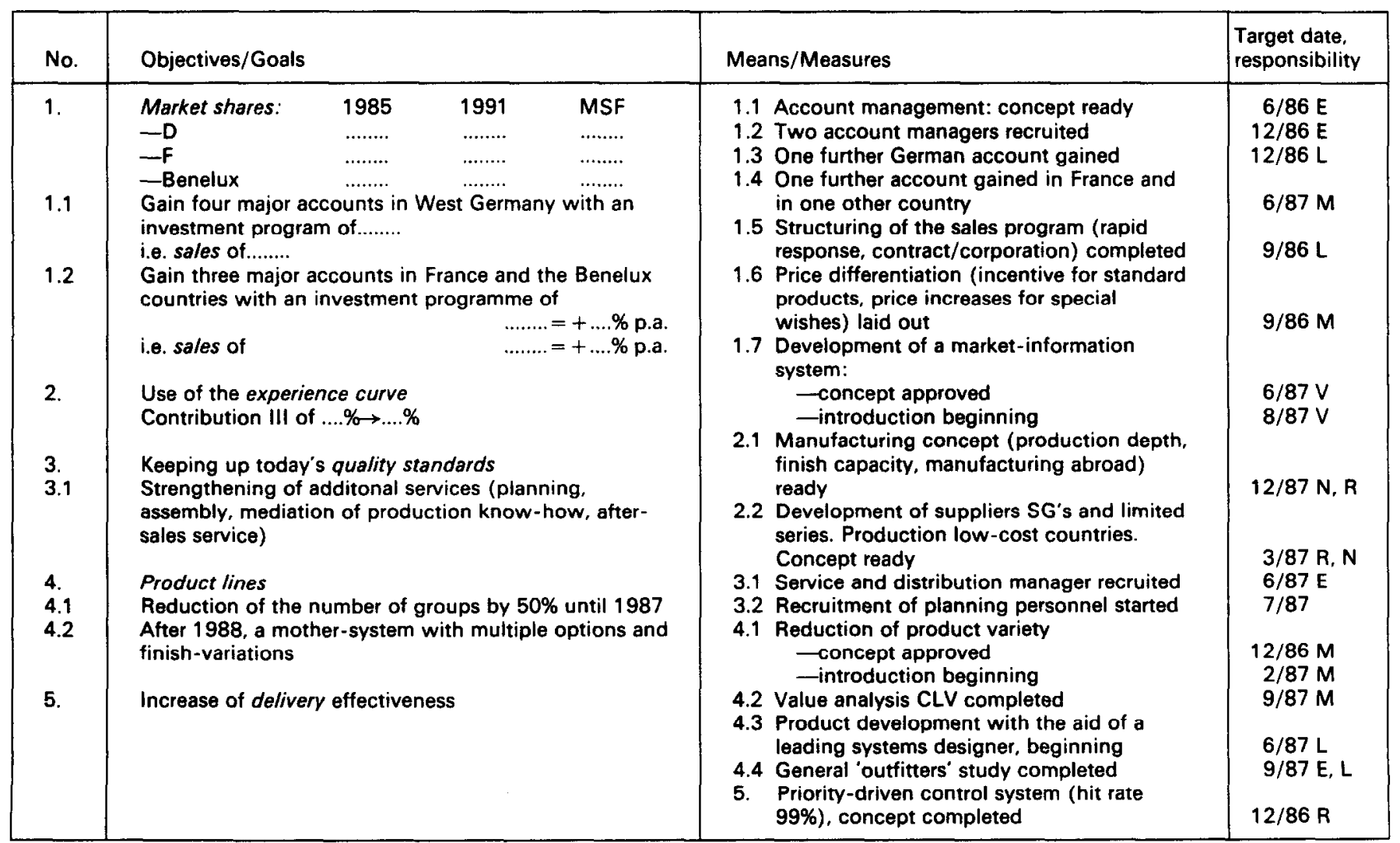



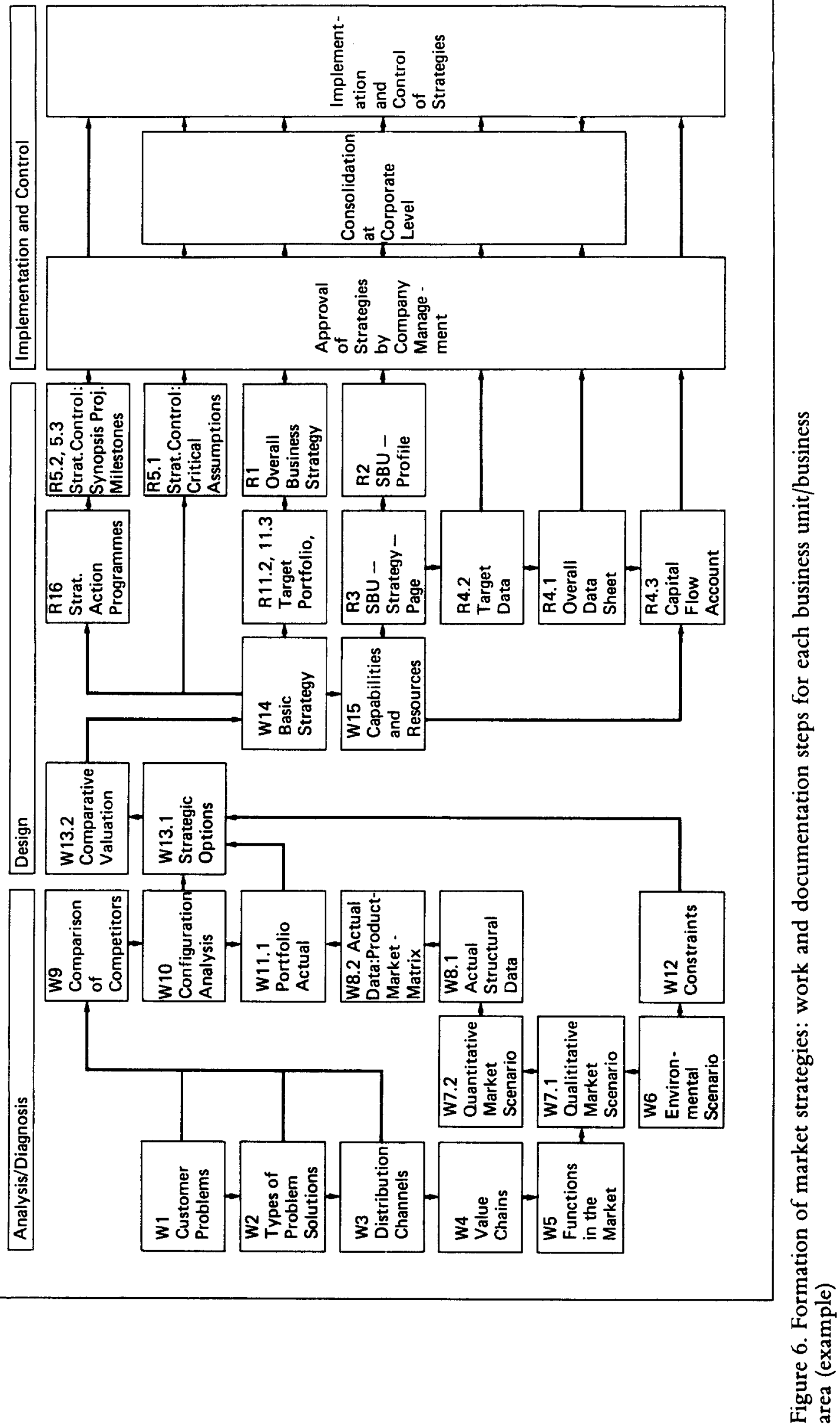
The creation of this instrument was based on insights provided by cybernetics, communication theory and brain research. This article allows room only to hint at some aspects of this theoretical basis and the benefits derived from this instrument:

(a) It promotes an integrative and systemic approach to the development of strategies. This not only aids consistency between goals and resources but also facilitates a way of thinking that reaches beyond one's own functional or divisional unit-an imperative for planning on a strategic level.

(b) Wordy or unclear strategy texts are avoided. The Strategy Page gives an immediate synopsis of the business strategy as a whole, of its important elements and their interrelationships. It is, therefore, also an instrument for effective communication, for example between the strategy team and top management.

(c) A concise and structured documentation of the substance of a strategy assists its implementation. This is only the case if the people responsible for putting the strategy into practice also take an active part in its development. It is important to guide the people involved towards a purposeful and effective implementation of the plan, by asking the 'right' questions, by concentrating on essentials and through using a structured approach throughout the process.

The financial impact of the strategy is quantified for each business unit in a long-range cash flow. The annual totals of the consolidated balances from all business units provide a forecast of cash shortages and surpluses, on the basis of which the financial viability of the strategies can be determined.

Much research and many methods have been dedicated to the quantification of the financial effects of strategies, but most methods for estimating financial requirements resulting from strategic decisions have been based largely on intuition and judgement. There are probably only two methods in this category which go significantly beyond the general state of the art. On one hand, pioneer work has been accomplished by the SPI-Strategic Planning Institute. SPI tools permit managers to ascertain the effects of a particular strategy, using the PIMS data base ${ }^{12}$ as an empirical resource. The effects of 37 parameters like 'product quality' and 'market share' on mid- to long-term ROI and cash flow are ascertained for specific cases through multivariate techniques. As the data base contains files of strategic data for about 3000 businesses, relatively high levels of statistical significance can generally be obtained in these calculations.

Significant progress was also made by Gaelweiler. Based on his theory of strategic management, he developed a method which uses cost theory and economic market theory to arrive at reliable estimations of cash needs resulting from specific strategies. ${ }^{13}$

A synthesis of these two approaches is under way, ${ }^{14}$ but there is still much work to be done to integrate quantitative methods into corporate planning. Examples of such methods which seem particularly useful are system dynamics, game theory and tensor mathematics. One of the major challenges for the coming years will be to overcome the barriers to communication between quantitatively oriented management scientists and managers. Significantly improved modelling software, available for microcomputers (for example the Stella package and the screen-driven version of Dynamo) will probably contribute to increasing acceptance and, hopefully, to spread the use of new quantitative tools among planners.

The formulation and the quantification of goals and strategies are necessary elements of effective strategy design. A precondition for successful implementation is that the action programmes and the key tasks which the strategy requires are documented according to type and project:

t5 Estimating expenditure in man-days and money.

Specifying important strategic milestones.

is Determining the persons responsible.

$\rightarrow$ Re-timetabling the deadlines and milestones.

These requirements seem obvious. Yet, in many European companies strategy is still viewed as an area limitcd to goal formulation. Frcquently, top management formulates goals and allocates resources, whilst the elaboration of action programmes is delegated to others. As I have shown elsewhere, ${ }^{15}$ such a separation often leads to alienation of personnel and the adoption of unrealistic strategies.

The Strategy Page shown in Table 1 should also be understood as an effort to prevent this kind of alienation, because goals, resources and actions are stated together.

\section{Work and Documentation}

A synopsis of the work and documentation procedures which are necessary to plan new business strategies is shown in Figure 6. Iterations are left out in the diagram. The instruments discussed hitherto are parts of this sequence.

The steps shown in this diagram are based on two main foundations:

(1) On Gaelweiler's theory already mentioned, which contains a comprehensive model of strategic parameters and their interrelationships. 
(2) On successive testing of this theory's propositions with competing theories, as well as with the practical requirements of consulting and managing. ${ }^{16}$

The sequence of the steps in the process shown is defined by the logical structure of the interrelationships between strategic parameters. The order of succession plays an important part with regard to both efficiency (rationality of the planning work) and effectiveness (achievement of sustainable plans). The degrees of detail and formalization of the working tools (computer software, forms, checklists etc.) for each step naturally vary according to the size and diversity of the business.

The steps shown in Figure 6 are guidelines. Their purpose is to ensure that critical points are not left out in the process of planning. In the light of experience I consider all the steps shown in Figure 6 (except steps 11.1, 11.2 and 11.3, which are useful mainly for visualization) to be fundamental to the process. Since the omission of any one of these steps would incur substantial risk of error in most cases, all of them are necessary. Particular situations may require further subdivisions of the steps outlined or the adoption of additional steps, such as highly specific analyses, for example Quality Charting, Dynamic Industry Profiles, or the explicit formulation of constraints (from higher level decisions in a large organization, or from governmental regulations). Throughout the process of analysis, diagnosis and design, the use of feedback and network diagrams has proved helpful in producing a deeper understanding of the causes and effects, the interdependencies between different elements and the sensitivities of the variables.

The process described here has been used in a number of corporations. It is, for example, being implemented at the present time in a large company of the service sector. In this case, each of the working steps is documented with a specific form, some required report forms (' $R$ '), some optional working papers, ('W') - and a checklist. In my experience, this kind of documentary support is very useful in instituting rational mental processes for analysis, synthesis and design. However, it does not provide a solution to two fundamental problems:

(1) It does not guarantee a deeper understanding of strategic issues. To spread this understanding, much more thorough training of people involved in planning is needed.

(2) It may help, during the planning process, to focus discussion onto key issues, but this cannot solve problems associated with human relationships, conflicting interests, assertion of power, resistance to change and organizational inertia. I shall return to these socio-psychological aspects of planning methodology in the final section.

\section{The Social Psychology of Planning}

At the beginning of this article, the function of a methodology of strategy development was defined as the management of mental processes. These processes, aimed at developing knowledge, are of both an individual and a collective nature. Individuals think, but from a systems perspective, a group or an organization also has its own specific ethos, mind and intuition. ${ }^{17}$ It goes through perception processes and develops its own conceptual frameworks. When designing planning methods, all three levels must be taken into account: the knowledge-gaining processes, which in the end determine the effectiveness of a strategy, not only evolve (1) in the minds of individuals but also (2) in the 'mind' of the strategy team as a whole and, finally (3), in the organizational 'mind' as a producer of what we perceive as emergent strategies. The interest of researchers and process facilitators in organizational thinking has been growing in recent years.

From a logical pont of view, a methodology of strategic planning has a structuring, a 'programming' and hence an anticipative, control function. It must guarantee that all the important parameters, components and the interrelationships are considered. Normally, the results of the planning activity are no better than the model on which they are based. A diagnosis of the initial stratcgic situation, for example, affects all further planning phases. If it is made without taking into consideration certain phenomena which have long-term effects (e.g. the dynamics of technological substitution, experience curves and value chains), then the probability is high that the wrong conclusions will be drawn. Therefore, a methodology must ensure that no important questions are missed out during the process of analysis, diagnosis and strategy design.

Although this gives no guarantee of getting to the 'right' results, it does at least provide favourable conditions for effective planning.

From a socio-psychological viewpoint, a methodology of strategy development should enable a realtime control. Recently, attention has been focused increasingly on the decisive role of interaction and communication between the people involved in the planning process. This has resulted in the methodology of 'process control' becoming an integral part of strategic planning methodology.

The evolutionist theory of knowledge,$^{18}$ has turned out to be a useful model for process control. ${ }^{19}$ From this perspective, the process of finding strategies is a form of problem solving, i.e. a knowledge-gaining process. It is also a cognitive process (from 'cognitio', becoming acquainted with, recognition, knowledge) and it is 'seamless', i.e. without a 
beginning or end. ${ }^{20}$ The progression of knowledge, in the sense of institutional learning, is achieved through a social process which is largely political and psychological. Many companies have started to learn how important it is to have those responsible for the implementation of a strategy participate in its formation, not only in order to gain their approval, but also to maximize the collective know-how available for the design of a corporation's future. ${ }^{21}$

The political dimension of strategy-making processes is indicated in conflicts of interests, negotiations and the search for a reasonable consensus. The controller or 'coach' of this process has to ensure that an interactive discussion takes place, in which all relevant arguments, not only those of the most powerful parties, are considered. It is important to avoid 'easy' compromises and to ensure that strategic decisions are made on the basis of sufficient knowledge and understanding of the problem.

The social psychology of planning has its own rules which cannot be explained or understood from a purely technical standpoint. The phenomena of perception, such as reinforcement, distortion and projection mechanisms, can lead to conflictswhich damage the company. Due to bias or prejudice, the available data material may be misinterpreted and the initial situation wrongly assessed. This will lead to the development of a poor strategy. In such a case, a progressive rate of error occurs not in spite of, but because of consensus of the participants, who reinforce one another's belief in a poor decision. Competent control, 'coaching', of the planning process can, however, counteract such tendencies. The process facilitator's role is to reinforce the self-organizing process, so that the struggle with a strategic problem will lead to a higher level of knowledge.

The planning 'software' consists, therefore, not only of forms, checklists and computer programmes but also of the concepts, methodology and ability of the process controller.

On the strategic level this knowledge is abstract. It is, therefore, all the more important to supplement concepts and methodology with the business knowhow of the individuals who participate in the planning process. Otherwise there is a continual danger of coming to the wrong conclusions. The role of business expertise is to enable problems to be solved efficiently, whilst conceptual expertise prevents the wrong problems being solved.

\section{References and footnotes}

(1) The picture in Figure 1 is similar to the human head with its two brain halves (seen from above). This analogy is based on the following analysis: proactive control is a future-oriented function, more in accordance with the left hemisphere of the brain (logical, sequential, language-oriented); the control of social processes, on the other hand, requires rather the abilities attributed to the right hemisphere, such as the capacity for integration, thinking in terms of pictures and patterns and the related characteristics of spontaneity and intuition.

(2) For example: Colin Camerer, Redirecting research in business policy and strategy, Strategic Management Journal, 6, 1-15 (1985); David B. Jemison. The importance of an integrative approach to strategic management research, Academy of Management Review, 6, 601-608 (1981)

(3) Markus Schwaninger, Management-Entwicklung (Management development), Die Unternehmung, 38, $231-243$ (1981).

(4) Stafford Beer, Brain of the Firm, 2nd edn, p. 402. John Wiley, Chichester (1981)

(5) An earnings potential is defined as the set of prerequisites for long-term economic success of a business or company. Compare: Aloys Gaelweiler, Die Strategische Führung der Unternehmung (Strategic corporate management), in Handbuch des Kaufmännischen Geschäftsführers, Moderne Industrie, Munich (1979); Aloys Gaelweiler, Strategische Unternehmensführung (Strategic Management), compiled and edited by Markus Schwaninger, Campus. Frankfurt (1987)

(6) James W. Frederickson, Strategic process research: questions and recommendations, Academy of Management Review, 8 , 565-575 (1983)

(7) The tendency to decentralize strategic planning efforts, to strengthen planning functions within the line and to reduce central planning staffs is without doubt the result of managers having learned more about how to plan (see The new breed of strategic planner, Business Week, September 17, 52-57 (1984)). However, one should not revert to the error of generally mistrusting planning methodology, as such.

(8) Compare: Ulric Neisser, Cognition and Reality, Freeman, San Francisco (1976); H. P. Dachler, Towards a psychology of social systems, Working paper, St. Gall Graduate School of Economics, Law, Business and Public Administration (1982).

(9) Markus Schwaninger, Sottware No. 87023, St. Gall Mangement Centre, July 1980; see also: Roberto Buaron, New game strategies, The McKinsey Quarterly, 24-40. Spring (1981).

(10) The 'Strategy Page' shown in Table 1 was developed at the St. Gall Management Centre by the author, together with F. Malik and A. Malaer.

(11) Detailed survey forthcoming.

(12) PIMS is the abbreviation for Profit Impact of Marketing Strategy.

(13) Aloys Gaelweiler, Zur Abstimmung zwischen Unternehmungsstrategie und Finanzierungspotential (Timing strategy and financial potential), in Armin Töpfer and Heik Afheldt (Eds), Praxis der strategischen Unternehmensplanung (The Practice of Strategic Planning), pp. 246-297, Metzner, Frankfurt (1983).

(14) A joint venture of PIMS/SPI and MZSG (St. Gall Management Centre), an institution which puts Gaelweiler"s theoretical concepts into practice, has been operating for several years. See Markus Schwaninger, Das MZSG-PIMS-Konzept der Strategie-Entwicklung (The MZSG/PIMS-concept of strategy development), St. Gall Mangement Centre (1985/86).

(15) Markus Schwaninger, Zur Gestaltung von Planungssystemen (On the Design of Planning Systems), Diskussionsbeitrag des Instituts für Betriebswirtschaft an der Hochschule St. Gallen, No. 9 (1985).

(16) Markus Schwaninger and Fredmund Malik, Strategiefindung (Strategy Design) (forthcoming).

(17) Compare: Henry Mintzberg and James A. Waters, The mind of the strategist(s), in Suresh Shrivastra and Associates (Eds), The Executive Mind, pp. 58-83, Jossey-Bass, San Francisco (1983).

(18) The theory in question states that progression of knowledge is achieved through continual, critical struggle with problems, through the rejection and changing of existing theories as well as the development of new ones. Compare: Karl R. Popper, Objective Knowledge. The Clarendon Press, Oxford (1972).

(19) For the purpose of problem-solving methodology, Popper's evolutionist theory of knowledge displays substantial benefit 
compared to available alternatives (mainly inductivist and subjectivist epistemologies). For relevant argumentation see Karl R. Popper, Objective Knowledge; Peter Gomez, Fredmund Malik and Karl-Heinz Oeller, Systemmethodik (System Methodology), part A, Haupt, Bern (1975); Hans Albert, Traktat über rationale Praxis (Tract on Rational Practice), Mohr, Tübingen (1978).

(20) Compare: Aloys Gaelweiler, Stratepische Unternehmensführung. Chapter XII; Markus Schwaninger, Bausteine für eine Methodik der Strategiefindung (Building blocks for a methodo- logy of strategy development), Working paper, St. Gall Management Centre, February (1984); Methodik der Strategieplanung (Strategic planning methodology), Harvard Manager, III, 54-61 (1985).

(21) I perceive Ackoff's concept of a 'circular organization' as representing the most advanced model currently available in terms of maximizing information processing capacity and integration of organizations through participative planning and policy-making. See Russell L. Ackoff, Creating the Corporate Future, pp. 163-168, John Wiley, New York (1981) 